\title{
Simulation model for planning renal services in a district health authority
}

\author{
P G Bolger, R Davies
}

\begin{abstract}
Objective-To investigate the use of a computer simulation model in planning and budgeting for renal replacement services.

Setting-Regional renal unit.

Results-The simulation provided projections that accurately reflected the actual numbers of people maintained on different forms of renal replacement therapy in previous years. Projections up to the end of the century showed that with no change in the demand for the service the total number of people on the renal replacement programme would increase by $40 \%$. Increasing the uptake of new patients from $\mathbf{4 0}$ per million to 55 per million would mean an increase of $66 \%$ in patient numbers over the same period. Similarly, at present day prices the cost of providing the service would rise by $31 \%$ with no change in demand and by twice this with the greater uptake of new patients. Increasing the number of transplant operations was shown to offer little prospect of a reduction in these costs.

Conclusion-The simulation program could be used by individual renal units to evaluate different treatment policies and to budget for resource use. Even at current demand levels resource requirements for renal replacement therapy will continue to grow until after the end of the century.
\end{abstract}

\section{Introduction}

Until the middle of this century renal failure was almost invariably terminal. Haemodialysis became available with the commercial development of Kolff's equipment ${ }^{1}$ in the 1950 s and came into widespread use for end stage renal failure in the 1960s and 1970s. Peritoneal dialysis was an alternative method of treatment but, before the late 1970s, was of limited use because it had to be given in hospital and was associated with high infection rates. The more recent development of continuous ambulatory peritoneal dialysis has provided a genuine alternative to haemodialysis because it enables patients to live and continue treatment at home. The use of continuous ambulatory peritoneal dialysis has extended the availability of treatment to diabetic and older people, groups previously excluded because of concern about prognosis on haemodialysis and lack of resources. ${ }^{23}$

There has been an increase in the number of people on the dialysis and transplant programmes of the United Kingdom brought about by changes in criteria for people thought suitable for dialysis, new technology and drugs giving rise to better survival figures, and political pressure to direct more resources into providing renal replacement therapy..$^{46}$ In 1981, 25 new patients per million population started on the dialysis programmes of England and Wales. In 1984 the Secretary of State for Health announced a target for regional health authorities of accepting at least 40 new patients per million population by $1987 .{ }^{7}$ By 1986 the United Kingdom had exceeded this target with an average of 47 new patients per million population.

Southmead Hospital, Bristol, provides renal replacement services for much of the northern part of the South Western region, parts of Wessex region, and to a few patients from further afield. It accepted its first patient for renal replacement therapy in 1966, and by 1977 it had 190 patients on the programme either on haemodialysis (home or hospital), or on continuous ambulatory peritoneal dialysis, or with a functioning kidney transplant. By 1989 the number of new patients commencing renal replacement therapy had increased to 77 per year (approximately 40 per million population), with a total of 529 people being maintained on the programme.

The legislation arising from the Working for Patients white paper $^{8}$ has divided health authorities into purchasers and providers of health care and requires that they must enter into contracts for the provision of medical services. In order to do this properly both purchasers and providers need to be able to predict future service demands and be able to evaluate the effects of treatment and policy decisions on resource requirements including costs. In the provision of renal replacement services planning is particularly important because much of the expense is generated by increasing numbers of chronic patients who continue to depend on expensive treatments and have intermittent requirements for hospital services for the rest of their lives.

\section{Method}

SIMULATION MODEL

In order to plan and budget services provided by Southmead a computer simulation model was chosen, based on the simulation written for the European Dialysis and Transplant Association. ${ }^{9}$ This model runs on an IBM personal computer, AT or PS/ 2 compatible, and describes the progress of patients through different modes of treatment over time up to a maximum of 10 years. Figure 1 shows the transfer of patients between different modes of treatment in the simulation program. This model was thought to be preferable to other models, such as the one used in Manchester ${ }^{10}$ and various Markov models, ${ }^{112}$ because it represents the system more accurately and allows many different assumptions to be tested. ${ }^{13}$ For example, in describing the transfer of individuals from one treatment to another it takes into account constraints on the resources available, individual patient characteristics (such as age and risk group), transplant availability, and graft matching. Furthermore, the results can be subdivided by age group or purchasing health district if required.

A simulation model describes the movement of items (in this simulation the items are patients) 


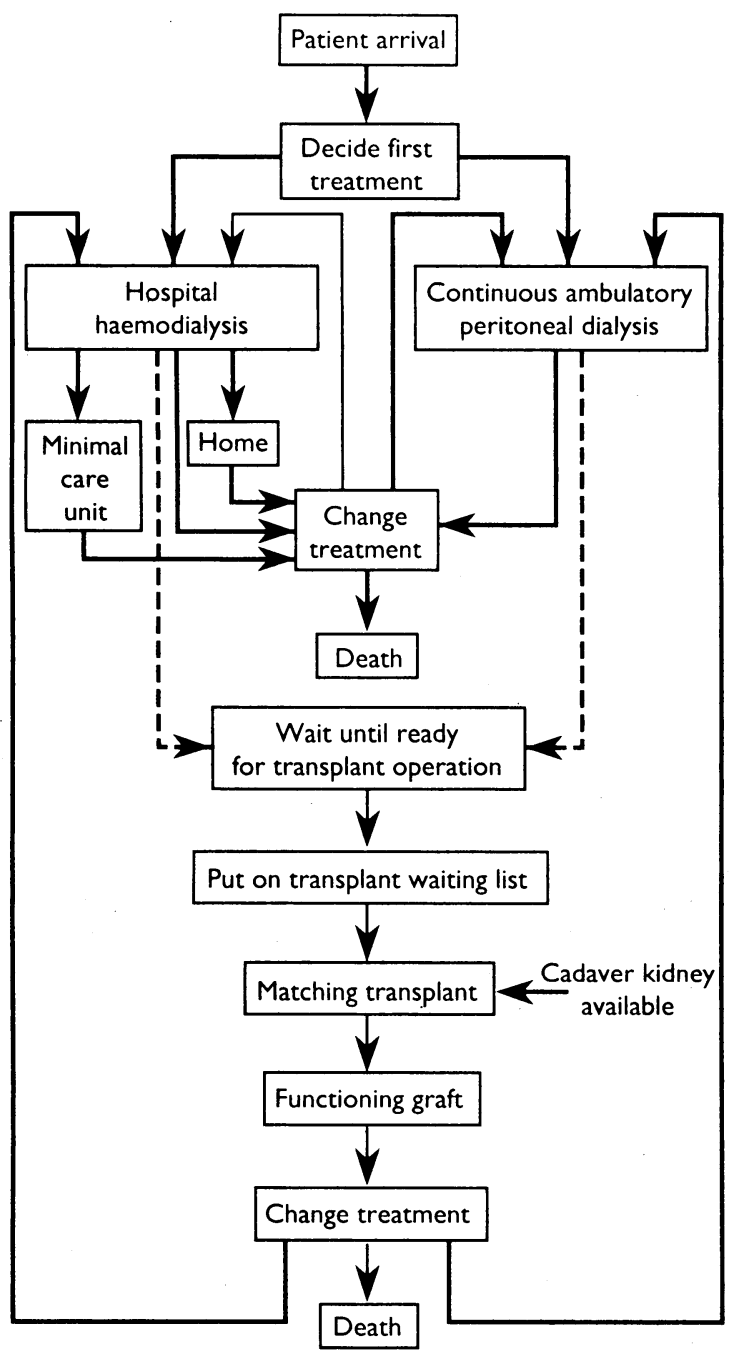

FIG 1-Flow diagram showing movement of patients between states in simulation model
(3) In order to prevent unrealistic queues building up in the simulation for any particular treatment some flexibility between treatments was introduced into the model. The simulated patients could be allocated a preferred first treatment, depending on their age or risk group, but if there were insufficient places for new patients requiring haemodialysis they would start continuous ambulatory peritoneal dialysis, or viceo versa. Places would be found exceeding the "upper limit" if necessary for patients already under treatment. - for example, those returning to haemodialysis with failed graft. If an upper limit on home dialysis placeso was reached patients would continue to receive unic dialysis until places became available.

(4) Inpatient treatment was not included in the simulation structure both because of the difficulty in obtaining sufficiently detailed data and also in the interests of keeping the model simple and fast. It was taken into account as far as possible in producing $\vec{\sim}$ treatment related costs.

In considering the assumptions it is importan to remember that they inevitably simplify what is:happening or is likely to happen in the future. The choice is thus a balance between, on the one hand or oversimplification and, on the other, more complexity (such as the use of different survival rates for each ${ }^{+}$ projected year) making the model more difficult tos provide with data, to test, and to interpret. The advantage of a simulation model is that, unlike $\mathrm{a}^{\mathrm{P}}$ Markov model, it is flexible and assumptions can be $\overrightarrow{0}$ changed..$^{13}$ For example, any of the first three assump $(s)$ tions listed above can be modified by small amend웅 ments to the program code. Additional codes can also be provided to describe the use of inpatient facilities, as has been done in a previous model. ${ }^{14}$ The model can thus be adapted quite easily to take account of differento treatment policies.

The model can produce up to 50 independeni simulation runs for each data set based on differen? random number streams. The results from any set os runs include averages and confidence intervals aboun those averages. The output is produced as a set of tables which can be fed into a spreadsheet for further analysis (including costing) and graphical output.

The simulation program has a menu structure which allows files of input data to be created or edited simulations to be run from validated data files, and output files to be inspected.

through a series of events which are assumed to happen at discrete points in time. The events in this simulation are the admission of patients to the dialysis and transplant programme, the arrival of transplants, the start and finish of activities such as long term home dialysis, and survival of patients with functioning transplants. The program samples patient survival, treatment time, treatment choices, and other decisions from probability distributions in order to determine the simulated patients' treatment times and their routes through the system. Those operating the simulation can enter the patient data to be used, the number of years to be simulated, the reporting interval, and the number of repeat runs.

Some of the assumptions discussed and agreed with clinicians and officers of Southmead Health Authority were:

(1) Survival rates would not change significantly during the period for which the projections were made (see below). In order to keep data entry to a minimum the model used only two data points from each treatment survival curve - that is, two survival values at two well spaced time points.

(2) The number of transplant operations performed was limited by the availability of cadaver kidneys. All other treatment modes could be constrained by fixing an upper limit on the number of places. For resources that were effectively unconstrained very large upper limits could be used.

\section{DATA FOR MODEL}

A computer database with information about all past and present patients on Southmead's renal replace $\varrho$ ment programme provided much of the input data for the simulation. The database provided estimates of the proportion of new patients starting on the differenn types of dialysis (haemodialysis $53 \%$, continuous ambulatory peritoneal dialysis $47 \%$ ), percentage o? people who would move to alternative mode of treat ment after failure (haemodialysis $38 \%$, continuou^ ambulatory peritoneal dialysis $39 \%$, grafts less than $\mathrm{w}$ year old $85 \%$, grafts more than 1 year old $58 \%$ ), the number of transplant operations performed, and the number of patients on each treatment mode at the stare of the simulation run. Survival curves were produced by using the life table analysis of the statistical package for the social sciences. For each treatment modeक percentage survival at two points in time were fed into the model. In the simulation for years after 1990 these were, for example, $83 \%$ at 40 weeks and $76 \%$ at $10 \varnothing$ weeks for haemodialysis, $81 \%$ at 50 weeks and $59 \%$ at 128 weeks for continuous ambulatory peritoneap dialysis, and $79 \%$ at 12 weeks and $72 \%$ at 100 weeks fo people with a graft.

Renal physicians at Southmead provided estimates of the percentage of new patients suitable for home 


\begin{tabular}{|c|c|}
\hline & $\begin{array}{c}\text { Cost } \\
(\mathfrak{E})\end{array}$ \\
\hline \multicolumn{2}{|l|}{ Graft (first year): } \\
\hline Transplant operation & 8922 \\
\hline Cyclosporin & 2772 \\
\hline Outpatient (25 visits) & 1692 \\
\hline Total & 13386 \\
\hline \multicolumn{2}{|l|}{ Graft (subsequent years): } \\
\hline Cyclosporin & 2772 \\
\hline Outpatient ( 5 visits) & 338 \\
\hline Total & 3110 \\
\hline Unit dialysis year cost ${ }^{\star}$ & 21606 \\
\hline \multicolumn{2}{|c|}{ Home haemodialysis (first year): } \\
\hline Building conversion & 1800 \\
\hline Year cost ${ }^{\star}$ & 8664 \\
\hline Outpatient (5 visits) & 338 \\
\hline Total & 10802 \\
\hline \multicolumn{2}{|l|}{ Home haemodialysis } \\
\hline Outpatient (3 visits) & 203 \\
\hline Year cost ${ }^{\star}$ & 8664 \\
\hline Total & 8867 \\
\hline \multicolumn{2}{|c|}{$\begin{array}{l}\text { Continuous ambulatory peritoneal } \\
\text { dialysis (first year): }\end{array}$} \\
\hline Year cost ${ }^{\star}$ & 7534 \\
\hline Outpatient (8 visits) & 541 \\
\hline Total & 8075 \\
\hline \multicolumn{2}{|c|}{$\begin{array}{l}\text { Continuous ambulatory peritoneal } \\
\text { dialysis (subsequent years): }\end{array}$} \\
\hline Year cost ${ }^{\star}$ & 7534 \\
\hline Outpatient (3 visits) & 203 \\
\hline Total & 7737 \\
\hline
\end{tabular}

^Annual contract price including use of erythropoietin. dialysis $(80 \%)$, the percentage who would be suitable for transplantation $(61 \%)$, and the maximum capacity of each treatment mode available at Southmead. The costings used were those being prepared by Southmead treasurers for inclusion in 1991-2 contracts. To produce a cost for the average patient by treatment mode (see table I) assumptions were made (with the help of the renal physicians) regarding average number of outpatient visits in each treatment mode and the use of cyclosporin and erythropoietin.

\section{VALIDATION OF MODEL}

In order to gain confidence that projections produced by the model were capable of accurately reflecting reality a validation exercise was undertaken. Data from the period 1983 to 1987 were used to devise the inputs for the model such as survival curves, average numbers of new patients started, and average number of transplant operations performed. These data were then used to project for the period 1988 to 1990.

\section{USE OF MODEL}

The simulation model was used to make predictions about the future numbers of patients under treatment. As the model is an extremely flexible tool decisions had to be made as to which assumptions to make. It is possible simply by changing the data entry figures to look at the effects of, for example, providing minimal care units, of increasing or decreasing the provision of home dialysis, or of using different survival values for different patient care groups.

The district was particularly concerned as to what might be the effect of an increase in the demand from an average of 40 per million population per year to 55 per million. This figure was used because it was a target suggested at the time by renal physicians in the South Western region. ${ }^{15}$ It almost certainly underestimates absolute need for dialysis, which has since been estimated at about 78 per million, ${ }^{16}$ but still represented a significant expansion in the service. Another concern was to explore the effects of increasing
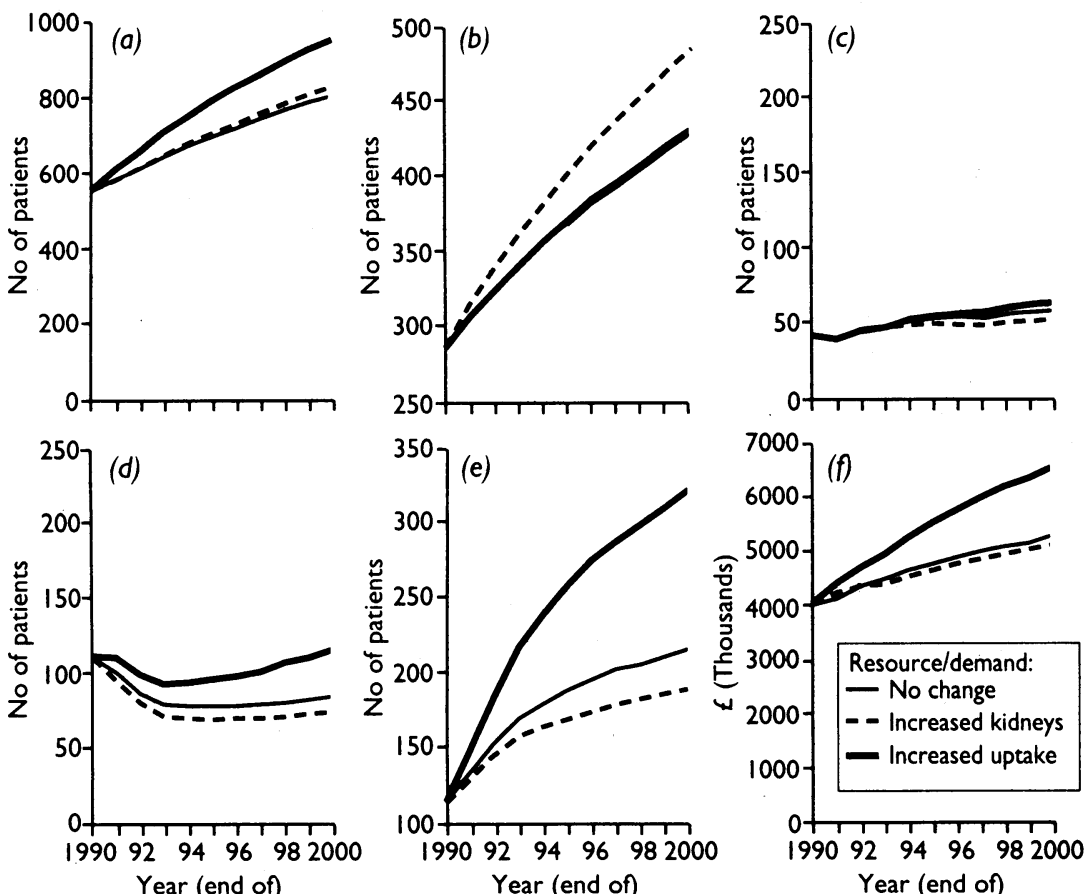

FIG 2-(a) Simulation projections of total number of patients on Southmead programme from year 1990 to $2000 ;(b)$ simulation projections of number of patients with functioning grafts on Southmead programme from 1990 to 2000; (c) simulation projections showing total number of patients on hospital haemodialysis on Southmead programme from 1990 to $2000 ;(d)$ simulation projections showing total number of people on home haemodialysis on Southmead programme from 1990 to 2000; (e) simulation projections showing total number of patients on continuous ambulatory peritoneal dialysis on Southmead programme from 1990 to 2000; $(f)$ costs based on simulation projections for workload on dialysis and transplant programme in Southmead district from 1990 to 2000
TABLE II - Projection using data 1983 to 1987, from 1988 to 1990 compared with actual patient numbers

\begin{tabular}{|c|c|c|c|}
\hline & Projection & $\begin{array}{c}95 \% \\
\text { Confidence } \\
\text { interval }\end{array}$ & $\begin{array}{l}\text { Actual } \\
\text { figures }\end{array}$ \\
\hline $\begin{array}{l}\text { Year 1988: } \\
\text { Functioning graft } \\
\text { Unit dialysis } \\
\text { Home haemodialysis } \\
\text { Continuous ambulatory peritoneal } \\
\text { dialysis }\end{array}$ & $\begin{array}{r}257 \\
36 \\
111 \\
99\end{array}$ & $\begin{array}{c}250 \text { to } 264 \\
29 \text { to } 43 \\
101 \text { to } 121 \\
89 \text { to } 109\end{array}$ & $\begin{array}{r}256 \\
38 \\
116 \\
95\end{array}$ \\
\hline Total & 503 & 492 to 514 & 505 \\
\hline $\begin{array}{l}\text { Year 1989: } \\
\text { Functioning graft } \\
\text { Unit dialysis } \\
\text { Home haemodialysis } \\
\text { Continuous ambulatory peritoneal } \\
\text { dialysis }\end{array}$ & $\begin{array}{r}274 \\
38 \\
108 \\
106\end{array}$ & $\begin{array}{c}261 \text { to } 287 \\
32 \text { to } 44 \\
92 \text { to } 124 \\
91 \text { to } 121\end{array}$ & $\begin{array}{r}282 \\
39 \\
111 \\
99\end{array}$ \\
\hline Total & 526 & 510 to 542 & 531 \\
\hline $\begin{array}{l}\text { Year 1990: } \\
\text { Functioning graft } \\
\text { Unit dialysis } \\
\text { Home haemodialysis } \\
\text { Continuous ambulatory peritoneal } \\
\text { dialysis }\end{array}$ & $\begin{array}{r}291 \\
39 \\
105 \\
116\end{array}$ & $\begin{array}{c}278 \text { to } 304 \\
35 \text { to } 43 \\
89 \text { to } 121 \\
97 \text { to } 135\end{array}$ & $\begin{array}{r}287 \\
39 \\
111 \\
117\end{array}$ \\
\hline Total & 551 & 533 to 569 & 554 \\
\hline
\end{tabular}

the availability of cadaver kidney transplants. The scenarios tested were therefore (1) maintaining the current Southmead averages (scenario 1) - that is, an average of 40 new patients per million population starting renal replacement therapy and 45 kidneys available for transplantation per year; (2) increasing the average intake for new patients from 40 to 55 pe million population per year while maintaining 45 kidneys available per year (scenario 2); (3) increasing the number of cadaver kidneys available for transplantation from 45 to 55 per year while maintaining the current average intake rate (scenario 3 ).

Under each of the scenarios the following constraints were set: (1) there were no minimal care or satellite units available; (2) the number of home dialysis places was limited to 130 ; (3) there was no upper limit on continuous ambulatory peritoneal dialysis places; $(4)$ there would be no expansion in the number of places in the dialysis unit (currently 39 ) except to provide for existing patients requiring urgent treatment.

\section{Results}

VALIDATION OF MODEL

Table II shows the results of the validation simulation for the year 1988 to end of 1990 compared with actual figures. The results show good agreement between predicted and actual results.

\section{PROJECTIONS 1990 TO END OF 2000}

Figure $2(a)$ shows that by maintaining the current average intake of patients (scenario 1) the numbers of patients on the programme may be expected to increase by approximately $40 \%$ over a period of 10 years. With an increase in the average intake of patients (scenario 2) the model predicted a $66 \%$ expansion in patient numbers over the same period. Increasing the availability of cadaver kidneys (scenario 3), on the other hand, was predicted to have little effect on the total numbers predicted in scenario 1 .

Figure $2(b)$ shows that the projections of the numbers of patients with functioning grafts were affected by the availability of kidneys (scenario 2 ) but were unaffected by the average intake rate (scenario 3 ) This was because there were long waiting lists for transplant operations projected in all three scenarios. Thus in all the projections almost all the kidneys that became available could be matched to waiting patients. 
Figure $2(c)$ shows that the hospital unit was predicted to be working over capacity for most of the time. In the model this prevented many new patients for whom haemodialysis was the preferred treatment mode from starting haemodialysis; these patients started continuous ambulatory peritoneal dialysis instead. The predicted number of home dialysis patients thus fell, but rose again after a dip in 1994 or 1995 (fig $2(d)$ ).

Figure $2(e)$ shows that the number of continuous ambulatory peritoneal dialysis patients was predicted to rise throughout the 10 year period. In scenario 3, where there was an increase in the number of patients entering the programme with no increase in cadaver kidney availability or change in the size of the unit dialysis facilities, the projected numbers of patients on continuous ambulatory peritoneal dialysis doubled in only three years.

Figure 2(f) shows the costs (provided by Southmead treasurers) applied to these projections. With the current average intake of patients the costs of the programme can be expected to rise from $£ 4.0$ million at the end of 1990 to $£ 5.2$ million in 2000 (a $31 \%$ rise). Increasing the intake rate to 55 patients per million population can be expected to double the increase in costs. An increase in the transplantation rate appeared to have effected a small reduction on the overall cost predictions, amounting to $£ 680000$ (undiscounted) over the 10 years. In addition to these costs, there will clearly be a need to increase the size of the hospital dialysis unit or to provide minimal care units for those patients unsuitable for home dialysis. The effects of proposed developments such as these can be further evaluated by the simulation model.

\section{Discussion}

One of the effects of providing health authorities and general practitioners with budgets to buy health care for their patients is that they will have to, quite explicitly, ration the availability of certain services. Both purchasers and providers will thus need mechanisms for exploring different policy decisions and seeing the effects on costs and patient survival. The simulation model enables this to be done for those patients with renal failure.

The results from the few illustrative simulation runs discussed in this paper indicate that with the current uptake of patients on to the renal replacement programme the total number of people maintained and their associated costs will continue to rise over the next 10 years. If health authorities wish to maintain the current level of uptake either the resources in contracts issued to providers will need to increase year on year or providers will have to decrease costs. The results from this study indicate that there is little prospect of a substantial reduction in costs from an increase in the availability of transplants.

It is clear, therefore, that contracts issued for this service should recognise this position, and if districts wish the current uptake rates to be maintained they will have to find the resources for doing it. An increase in the uptake of new patients to 55 per million population per year (or more) would require health authorities to increase the money provided for this service substantially and for them to recognise that this sum would need to be increased every year until well after the year 2000 .

Predictions of future activity are clearly dependent on the continuing validity of the assumptions made in the model and accuracy of the data used. Significant unforeseen changes - for example, an increase in transplantation rate or new patients starting - will of course lead to errors in projections. However, the verification w of this model showed that it was possible to get good agreement between predicted and actual results. In addition, because the simulation model is flexible $\stackrel{\vec{D}}{+}$ it has potential for providing information about a wide variety of different scenarios and underlying assumptions that might be of interest to providing or $\frac{\rho}{\vec{D}}$ purchasing authorities. These might include the effect of some purchasing authorities taking their "custom" ঋ away from the renal unit (or vice versa); the admission of increasing numbers of elderly patients requiring continuous ambulatory peritoneal dialysis; the intro- $\vec{\omega}$ duction of new treatments which change patient $\stackrel{\circ}{\circ}$ survival or treatment costs; and the introduction of minimal care units with haemodialysis facilities.

One of the difficulties in the past has been the of availability of good patient data with which to run the simulation. Most renal units now, however, have of databases and reliable survival data. Data can be transcribed quite easily into the simulation program. of The simulation can thus be used by individual renal $\mathrm{O}$ units to evaluate different treatment policies and to budget future resource use.

We are grateful to Huw Davies, of Dundee University, who did much of the development work and programming; Dr Stuart Parker, of the renal unit at Southmead, for help in data $\underset{\mathbb{D}}{ }$ extraction; and Sue Quants, of the finance department, Southmead Hospital, for providing cost figures. The original $\vec{c}$ development work was funded by the Medical Research of Council in a cooperative project with the European Dialysis and Transplant Association Registry, London.

1 Ford C. A profile of Willem J Kolff. Dialysis and Transplantation 1976;5:15

2 Taube DH, Winder EA, Ogg CS, Bewick M, Cameron JS, Rudge CJ, et al. Successful treatment of middle aged and elderly patients with end stage renal disease. $B M 7$ 1983;286:2018-20

3 Laing W. End stage renal failure. London: Office of Health Economics, 1980, (Briefing paper No 11).

4 Pincherle G. Services for patient with chronic renal failure in England and Wales. Health Trends 1977;9:41-4.

5 Dowie R. Deployment of resources in treatment of end stage renal failure in England and Wales. BMF 1984;288:988-91. 6 Wood IT, Mallick NP, Wing AJ. Prediction of resources needed to achieve the

7 Patten J. Kidney patients. House of Commons official report (Hansard) $1984 \mathrm{Dec}$ 20;710: cols 309-10.

8 Working for patients. London: HMSO, 1989. (Cm 555.) 9 Davies H, Davies R. A simulation model for planning services for renal patients in Europe. Foumal of the Operational Research Society 1987;38: patients in Europe. Fournal of the Operational Research Society 1987;38:
$693-700$.

10 Wood IT, Mallick NP, Moores B. A flexible model for planning facilities for patients with end-stage renal failure $B M \mathcal{O}$ 1980;281:575-7.

11 Ludbrook A. Cost-effectiveness analysis of the treatment of chronic renal failure. Applied Economics 1981;13:337-50.

12 Shah AR, Foot SJ, Hollowell J. Renal replacement services planning-a mathematical approach. Lecture Notes in Medical Informatics 1981;11: $143-50$. 13 Davies $R$, Davies T. Using a simulation to plan health service resources:
discussion paper. $\mathcal{F} R$ Soc Med 1986;79:154-7. 14 Davies R. An interactive simulation in the health service. Fournal of $\bar{O}$
Operational Research Society 1987;36:597-606. 15 South Western Regional Health Authority. Towards a strategy for services for $\frac{0}{\mathbb{C}}$
chronic renal failure. Bristol: SWRHA, 1988 .

16 Feest TG, Mistry CD, Grimes DS, Mallick NP. Incidence of advanced chronic $\mathscr{S}$ renal failure and the need for end stage renal replacement treatment. $B M \mathcal{F}$ 1990;301:897-900.

(Accepted 8 fuly 1992) 